02

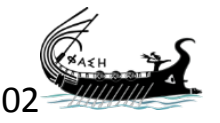

journal.phaselis.org

\title{
Olympos Kazısı 2009-2012 Yılları Bizans Sikke Buluntuları
}

\author{
Byzantine Coins Found During the Excavations at Olympos \\ 2009-2012
}

Zeliha DEMIREL GÖKALP

open 2 access journals

PHASELIS: Disiplinlerarası Akdeniz Araştırmaları Dergisi'nde bulunan içeriklerin tümü kullanıcılara açık, serbestçe/ücretsiz "açık erişimli" bir dergidir. Kullanıcılar, yayıncıdan ve yazar(lar)dan izin almaksızın, dergideki makaleleri tam metin olarak okuyabilir, indirebilir, dağıtabilir, makalelerin çıktısını alabilir ve kaynak göstererek makalelere bağlantı verebilir.

PHASELIS: Disiplinlerarası Akdeniz Araştırmaları Dergisi uluslararası hakemli elektronik (online) bir dergi olup değerlendirme süreci biten makaleler derginin web sitesinde (journal.phaselis.org) yıl boyunca ilgili sayının içinde (Volume II: Ocak-Aralık 2016) yayımlanır. Aralık ayı sonunda ilgili yıla ait sayı tamamlanır.

Dergide yayımlanan eserlerin sorumluluğu yazarlarına aittir.

Atıf Düzeni Z. Demirel-Gökalp, “Olympos Kazısı 2009-2012 Yılları Bizans Sikke Buluntuları”. Phaselis II (2016) 323-337. DOI: 10.18367/Pha.16023

Geliş Tarihi: 02.11.2016 | Kabul Tarihi: 24.11.2016 | Online Yayın Tarihi: 31.12.2016

Editörya Phaselis Research Project

www.phaselis.org 


\title{
Olympos Kazısı 2009-2012 Yılları Bizans Sikke Buluntuları
}

\author{
Byzantine Coins Found During the Excavations at Olympos 2009-2012
}

\author{
Zeliha DEMIREL GÖKALP*
}

Öz: Olympos antik kentinde, 2009-2012 yılları arasında "Giriş Kompleksi" ve "Köprü Caddesi" olarak adlandırılmış alanlarda gerçekleştirilen kazılarda toplam 35 adet bronz Bizans sikkesi bulunmuştur. Sikkelerin 31'i Erken Bizans, 4'ü Orta Bizans Dönemine tarihlendirilmektedir. Ele geçen sikkelerden 11'i çok yıpranmış ve aşınmış durumdadır ayrıca yazıtları da okunaksızdır. Aynı zamanda darphane ve imparatorları belirsizdir. Ancak özellikle arka yüzde belirgin olan birim işaretlerinden dolayı Erken Bizans Dönemi sikkeleri olduğu tespit edilmektedir. Olympos kazılarında ele geçen sikkelerin \% 42'si Konstantinopolis darphanesine aittir. Başkentteki darphane, kuruluşundan beri imparatorluğun bütün doğusuna sikke sağlayan ve bu bölgede en fazla üretimde bulunan darphane olma özelliği taşıdığı için Olympos’ta yüksek temsil edilme oranı oldukça normaldir. Konstantinopolis darphanesini \% 13 ile Antiokheia takip etmektedir. Erken Bizans Dönemi sikkelerinin \%10'u Nikomedia ve \% 3'ü (1 sikke) Kartaca darphanelerine aittir. Olympos kazılarında özellikle Balkanlara hizmet veren Thessalonika darphanesine ait sikke henüz ele geçmemiştir. Bunun ile birlikte, Kartaca gibi Batı darphanelerine ait 1 adet sikke bulunmaktadır. Olympos kazılarında bulunan sikkeler, Likya bölgesindeki diğer kentlerin kazı çalışmalarında ele geçmiş sikkeler ile istatistiksel olarak karşılaştırılmış. Arkeolojik kazıları gerçekleşmiş ya da devam eden kazılardan sadece Arykanda, Patara, Kaunos ve Dereağzı kazılarında bulunmuş Bizans sikke verileri karşılaştırmada kullanılmıştır. Likya bölgesinde, sınırlı sayıda kentlerin sikke buluntularını temsil eden örnekler üzerinden elde edilen veriye göre, kentler Erken ve Orta Bizans dönemindeki sikke sayısındaki artış ve Geç Bizans dönemindeki sikke sayısındaki düşüş ile paralellik göstermektedir.

Anahtar Sözcükler: Sikke · Bizans · Olympos · Likya

Abstract: In the ancient city of Olympos, 35 bronze Byzantine coins were found in the excavations carried out around the "Entrance Complex" and "Bridge Street". 31 of the coins are dated to be Early Byzantine Period while 4 of them to be Middle Byzantine Period. 11 of the coins found are fairly worn and eroded and the inscriptions on them are not legible. Also their mints and emperors are not uncertain. But due to the unit marks conspicuous especially on the reverses, they are determined to belong to Early Byzantine Period. $42 \%$ of the coins found in the Olympos excavations belong to Constantinople mint. Because this mint in the capital is the one that provided coin for the entire Eastern block of the empire and that made the greatest production in the area, its high representation rate in Olympos is quite normal. Antiokheia follows right after Constantinople with $13 \% .10 \%$ of the Early Byzantine Period coins come from Nikomedia and $3 \%$ of them (1 coin) from Cartagena mint. The coin from the Thessalonica mint that provided service especially for the Balkan has yet to be found in the Olympos excavations. However, 1 coin belonging to the western mints, Cartagena, was found. The coins found in the Olympos excavations were statistically compared to the other coins found during excavations in the other cities around Lycia. Among the finished or ongoing archeological excavations only the data of the Byzantine coins found in the excavations of Arykanda, Patara, Kaunos and Dereağzı were used in the comparison. According to the data obtained from the samples representing the coin findings of cities limited in number in the Lycian area, the cities show paralellism with the increase in coin numbers in the Early and Middle Byzatine Period and the decrease in the Late Byzatine Period.

Keywords: Coin · Byzantine $\cdot$ Olympos · Lycia

* Doç. Dr., Anadolu Üniversitesi, Edebiyat Fakültesi, Sanat Tarihi Bölümü, Eskişehir. zdgokalp@anadolu.edu.tr 
Giriş $^{1}$

Olympos Antik Kenti, Anadolu'nun güneybatısında, Antalya'nın 80 km. güneyinde ve Toros dağlarının kıyıya dik indiği bir yerde bulunmaktadır. Kent, Olympos Çayı'nın (Akçay) oluşturduğu derin bir vadi içinde yer almaktadır. Olympos Çayı, Antik Çağ'da olduğu gibi günümüzde de kenti ikiye bölmektedir² (Fig. 1).

Olympos Antik Kenti'nde, 2009-2012 yılları arasında "Giriş Kompleksi" ve "Köprü Caddesi" olarak adlandırılmış alanlarda gerçekleştirilen kazılarda toplam 35 adet Bizans sikkesi (Fig. 2) ele geçmiştir. Sikkelerin 31'i Erken Bizans ve 4'ü Orta Bizans Dönemine tarihlenmektedir. Ele geçen sikkelerden $11^{\prime}$ i çok yıpranmış ve aşınmış durumda olduğundan yazıtları okunaksızdır. Aynı zamanda darphane ve imparatorları da belirsizdir. Ancak özellikle arka yüzde belirgin olan birim işaretlerinden dolayı Erken Bizans Dönemi sikkeleri olduğu tespit edilmektedir.

Sikkelerin 20'si "Giriş Kompleksi"nde bulunmuştur. "Giriş Kompleksi" Olympos antik kenti S5IX sektör adresinde kentin kuzey-batısında Kuzey Nekropol Kilisesi'nin kuzey-doğusunda yer almaktadır (Fig. 1). Doğu-batı doğrultusunda yamuk dikdörtgen plana sahip olan kompleksi güneyde Olympos Çayı sınırlamaktadır. Yapı topluluğu birbiri ile ilişkili 18 odadan oluşmaktadır (Fig 3). "Giriş Kompleksi"nde ele geçen sikkelerin tümü VI.-VII. yüzyıla tarihlenmektedir (kat. no. 1-3, 5, 8, 10-12, 14, 16, 19, 25-26, 28-29, 30-33, 35). Bu durum "Giriş Kompleksi" kazılarında tespit edilen yapı bakiyeleri ve seramik, maden gibi el sanatı ürünlerinin tarihi ile de paralellik göstermektedir. Söz konusu yapı topluluğunda, işlik olması muhtemel mekânlarda, kazılar sırasında çok sayıda LRA1 olarak adlandırılan amphora grubu ve pişmiş toprak kandiller ${ }^{3}$, tüccarların başlıca ekipmanı olan kantar kancaları ve sikke kontrol ağırlıkları ${ }^{4}$ bulunmuştur.

"Köprü Caddesi" kazılarında ise 15 Bizans sikkesi ele geçmiştir. Köprü Caddesi, kentin güneyinde S6-VI sektör adresinde (Fig. 2) yer almaktadır ${ }^{5}$. Sikkelerin $11^{\prime}$ i yine VI.-VII. yüzyıla (kat. no. $4,6-7,9,13,15,17-18,20,27,34)$ ve 4'ü XI. yüzyıla tarihlenmektedir (kat. no. 21-24). Orta Bizans dönemine tarihlenen sikkeler, Geç Antik Dönem sonrası" "kentin güneyinde bir hareketlilik olduğunu kanıtlar mı?" sorusu için, kentte devam eden kazıların sonuçlarını beklemek doğru olacaktır.

VI.-VII. yüzyIl arasına tarihlenen Erken Bizans Dönemi sikkelerinin 14'ü 40 nummidir. Bu sikkelerin $11^{\prime} i$ Konstantinopolis, 1'i Nikomedia ve 1'i Antiokheia darphanesine aittir. Kazılarda 11 adet 20 nummi ele geçmiştir. Oldukça yıpranmış ve aşınmış olan 20 nummilerin 6 'sı okunaksız olduğundan darphaneleri belirsizdir. Bunun yanında 1'i Konstantinopolis, 2'si Nikomedia ve 2'si Antiokheia darphanelerine aittir. 10 ve 5 nummiler düşük maden kaliteleri ve ebatları dolayısıyla

1 Olympos Antik Kenti kazıları 2006 yılından itibaren Prof. Dr. B. Yelda Olcay Uçkan başkanlığında sürdürülmektedir. Makalenin konusunu oluşturan sikkelerin yayınına izin verdiği ve sonsuz desteği için sevgili hocama teşekkür ederim. Olympos Kazıları, Anadolu Üniversitesi Bilimsel Araştırma Projeleri Komisyonunca kabul edilen 1106E 109 ve 1206E093 nolu projeler kapsamında desteklenmiştir.

2 Olympos antik kenti ve kazı tarihçesi için bk. Olcay-Uçkan et al. 2006; Parman - Olcay-Uçkan 2006, 587-599; Demirel-Gökalp - Yıldırım 2010, 367-370; Öztaşkın 2013; Olcay-Uçkan - Öztaşkın 2016, 274-287; OlcayUçkan 2016, 489-501.

3 Olcay-Uçkan 2016, 494.

4 Mekân 3'de ele geçen MS IV-VI. yüzyıllar arasına tarihlendirilen 2 sikke kontrol ağırlığı, yaklaşık aynı kotlarda MS VI. yüzyıla tarihlendirilen 9 adet Erken Bizans Dönemi sikkesi ile birlikte bulunmuştur.

5 Köprü Caddesi hakkında detaylı bilgi için bk. Olcay-Uçkan et al. 2011, 80-82; Öncü 2012, 273-284.

6 Kentte, şimdiye kadar gerçekleştirilen bilimsel çalışmaların sonuçlarına göre, MS VII. yüzyıldan sonra kentsel düzeyde bir yaşamın olmadığı kanısı hakimdir (Olcay-Uçkan - Öztaşkın 2016, 287). 


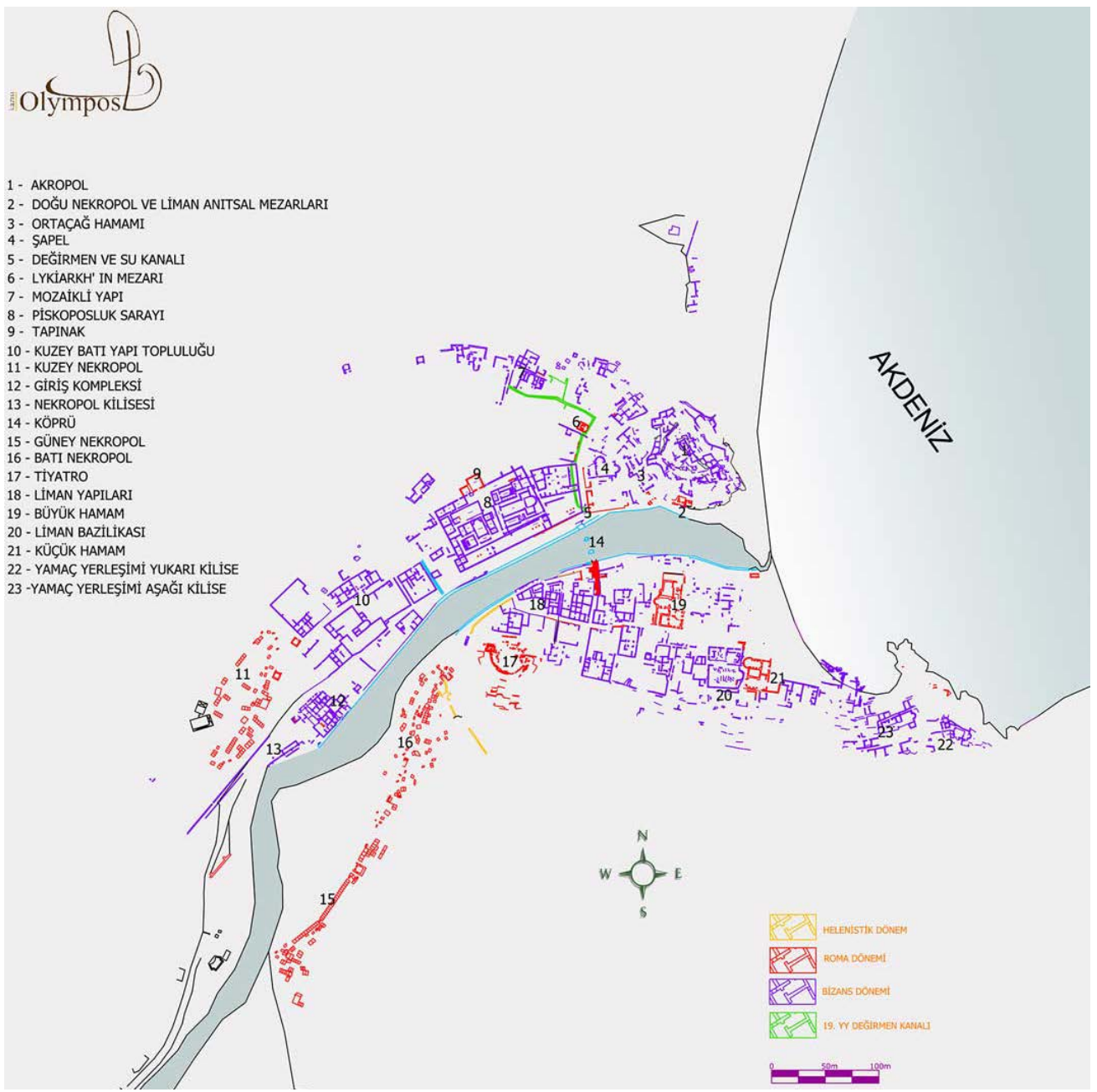

Fig. 1. Olympos Antik Kenti (Olympos Kazı Arşivi)

\begin{tabular}{|c|c|c|c|c|c|c|c|c|c|c|c|c|}
\hline \multirow{3}{*}{ İmparator } & \multicolumn{11}{|c|}{ Darphaneler ve Birimler } & \multirow{3}{*}{ Toplam } \\
\hline & \multicolumn{3}{|c|}{ Konstantinopolis } & \multicolumn{2}{|c|}{ Nikomedia } & \multicolumn{2}{|c|}{ Antiokheia } & \multirow{2}{*}{$\begin{array}{l}\text { Kartaca } \\
\text { Nummus }\end{array}$} & \multicolumn{3}{|c|}{$\begin{array}{c}\text { Darhanesi } \\
\text { Belirsiz }\end{array}$} & \\
\hline & 40 & 20 & 10 & 40 & 20 & 40 & 20 & & 20 & 10 & 5 & \\
\hline I. Iustinus (518-527) & 4 & & & & & & & & & & & 4 \\
\hline I. Iustinianus (527-565) & 3 & & 1 & & & & 1 & 1 & & & 1 & 7 \\
\hline II. Iustinus (565-578) & 1 & & & 1 & 1 & 1 & 1 & & & & & 5 \\
\hline Tiberius (582-602) & & & & & & 1 & & & & & & 1 \\
\hline Focas (602-610) & & 1 & & & 1 & & & & & & & 2 \\
\hline Heraclius (610-641) & 1 & & & & & & & & & & & 1 \\
\hline Erken Bizans Dönemi & 2 & & & & & & & & 6 & 2 & 1 & 11 \\
\hline Anonim B (1030/35-1042?) & 2 & & & & & & & & & & & 2 \\
\hline Anonim C (1042? - 1050) & 2 & & & & & & & & & & & 2 \\
\hline Toplam & 15 & 1 & 1 & 1 & 2 & 2 & 2 & 1 & 6 & 2 & 2 & 35 \\
\hline
\end{tabular}

Fig. 2. 2009-2012 Yılları Arasında Olympos Kazılarında Ele Geçen Bizans Sikkelerinin Imparator, Darphane ve Birimlere Göre Dağılımı 


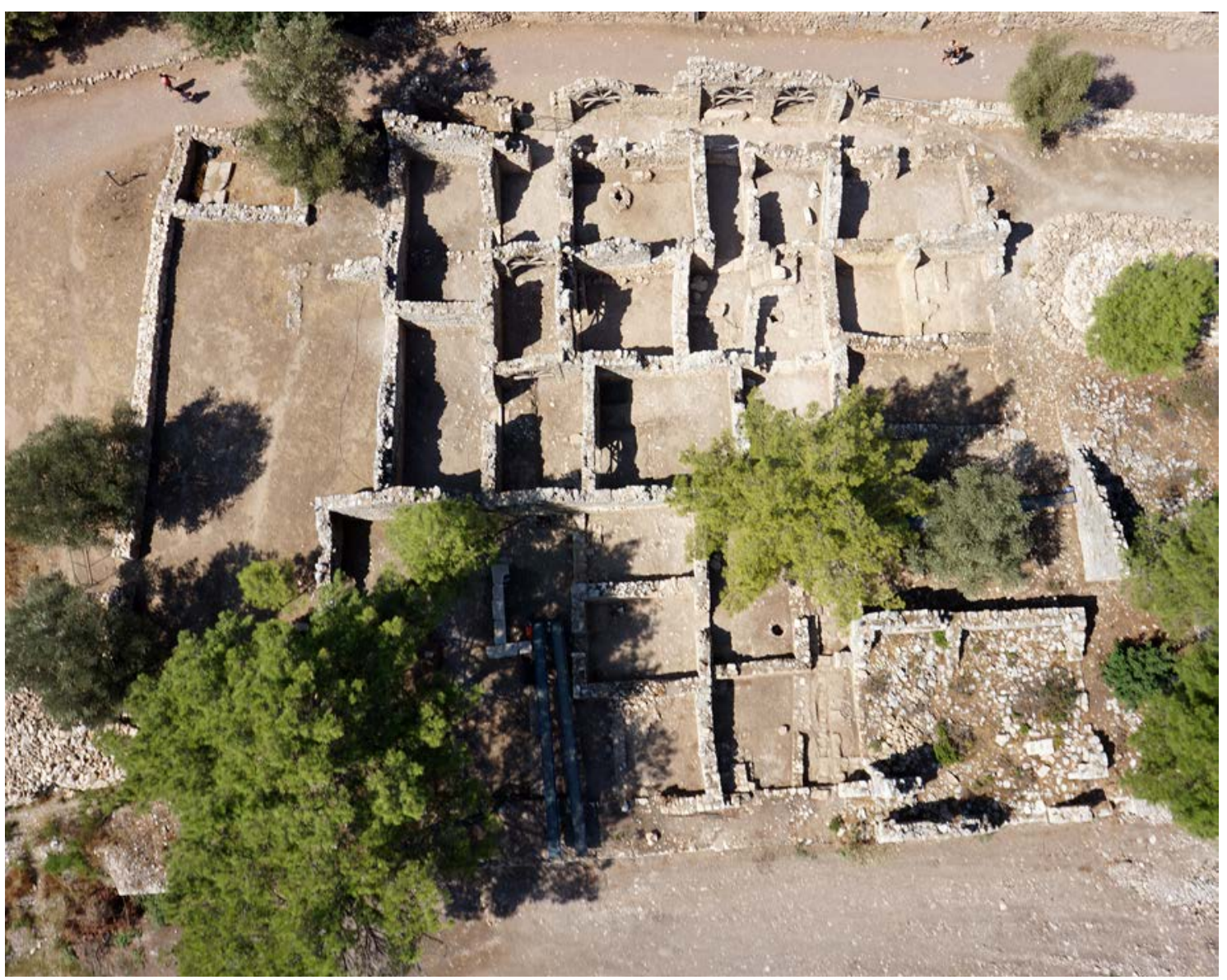

Fig. 3. Giriş Kompleksi (Olympos Kazı Arşivi)

\begin{tabular}{|c|c|c|c|c|c|c|c|c|c|c|c|c|}
\hline Darphane & \multicolumn{3}{|c|}{ Konstantinopolis } & \multicolumn{2}{|c|}{ Nikomedia } & \multicolumn{2}{|c|}{ Antiokheia } & Kartaca & \multicolumn{3}{|c|}{$\begin{array}{c}\text { Darhanesi } \\
\text { Belirsiz }\end{array}$} & Toplam \\
\hline Birim & 40 & 20 & 10 & 40 & 20 & 40 & 20 & Nummus & 20 & 10 & 5 & \\
\hline Sikke Sayısı & 11 & 1 & 1 & 1 & 2 & 2 & 2 & 1 & 6 & 2 & 2 & 31 \\
\hline
\end{tabular}

Fig. 4. Olympos Kazılarında Bulunan Bronz Sikkelerin Birimlere Göre Dağılımı

çoğu zaman tanımlanamayan grubu oluşturmaktadır. Olympos kazılarında ele geçen 2 adet 10 nummi ve 2 adet 5 nummi de tanımlanamamıştır. Bunun yanında 1 adet 10 nummi Konstantinopolis darphanesine aittir (Fig. 4).

Olympos kazılarında ele geçen sikkelerin \% 42'si Konstantinopolis darphanesine aittir. Başkentteki darphane, kuruluşundan beri imparatorluğun bütün doğusuna sikke sağlayan ve bu bölgede en fazla üretimde bulunan darphane olma özelliği taşıdığı için Olympos'ta yüksek temsil edilme oranı oldukça normaldir. Konstantinopolis darphanesini \% 13 ile Antiokheia takip etmektedir. Antiokheia darphanesinin yine imparatorluğun doğusuna hizmet ettiği düşünüldüğünde durum şaşırtıcı değildir. Erken Bizans Dönemi sikkelerinin \%10’u Nikomedia ve \% 3’ü (1 sikke) Kartaca darphanelerine aittir.

\section{Karşılaştırma ve Değerlendirme}

Olympos Kenti kazılarında bulunan Bizans sikkelerinin az sayıda olması nedeniyle, örnekleri 
istatistiksel olarak, kentin içinde bulunduğu Likya Bölgesi ${ }^{7}$ buluntuları ile karşılaştırmak yerinde olacaktır. Ancak Likya bölgesi kentlerinde ${ }^{8}$ arkeolojik kazıları gerçekleşmiş ya da devam eden kazılardan sadece Arykanda, Patara, Kaunos ${ }^{9}$ ve Dereağzı kazılarında bulunmuş Bizans sikke verilerine ulaşılmışırı. Bunun yanında Letoon ${ }^{10}$ kazılarında ele geçen sikkeler yayın aşamasında olduğundan ayrıca Andriake ${ }^{11}$, Limyra ${ }^{12}$ ve Demre-Myra Aziz Nikolaos Kilisesi ${ }^{13}$ kazılarında bulunan sikkelerin detaylı katalogları henüz yayınlanmadığından karşılaştırmaya / değerlendirmeye alınamamıştır. Ayrıca Likya Bölgesi'nde bulunan herhangi bir müzenin de yayınlanmış sikke koleksiyonu bulunmamaktadır ${ }^{14}$.

Olympos ve karşılaştırılacak olan Arykanda, Patara, Kaunos ve Dereağzı sikke buluntularına "periyot başına düşen sikke/periyot uzunluğu x 1000/bulunan toplam" formülü uygulanmıştır ${ }^{15}$. Sikkelere uygulanan bu formülde periyotlar için 13 dönem belirlenmiştir ${ }^{16}$. Olympos'un da dâhil olduğu beş buluntu örnekleri karşılaştırılmış ve elde edilen veriler (Fig. 5) grafiğe (Fig. 6) dönüştürülmüştür ${ }^{17}$.

7 Lykia, Vespasianus Dönemi (MS 69-79) başlarından itibaren yönetim merkezi Patara olan ve güney Pisidia’yı da içeren Lycia et Pamphylia çift eyaleti olarak yaklaşık 250 yıl değişmeden kalmıştır. Ancak MS 325 yılında gerçekleştirilen İznik Konsili'ne ait belgelerde Lykia ve Pamphylia'dan artık ayrı ayrı bahsedilmiştir. Bölgenin Osmanlı fethine kadar Bizans Dönemi hakkında detaylı bilgi için bk. Zimmermann 2016, 68-77.

8 Lykia Bölgesi kentleri için bk. Blum 2016, 136-141.

9 Kaunos, Bizans Dönemi deniz haritaları ve metinlerinde Karia'da kabul edilmesine karşın, kilise kayıtlarında Likya Eyaletine dahil 2 Piskopos ile temsil edilen bir yerleşim olduğu (Çizmeli-Öğün 2007, 55) için değerlendirilmeye alınmıştır.

10 Bk. Atik-Korkmaz et al. 2016, 72.

11 Andriake ile ilgili yayında, 2009-2012 yılları arasında Andriake kentinde gerçekleştirilen kazılarda 110 Bizans sikkesi bulunduğu (2'si altın, diğerleri bronz) bilgisi yer almaktadır. Ancak katalogda sadece 13 adet Bizans sikkesi verilmiştir. Dolayısıyla yayında hangi imparatorun kaç adet sikke ile temsil edildiği anlaşılamamaktadır. Bk. Bulut - Şengül 2014, 83.

12 Limyra için bk. Borchhardt 1999, 135-136. 2007 yılı Limyra kazı çalışmalarında incelenen ve tanımlanan Geç Antik ve Erken Bizans Dönemi'ne tarihlenen 30 adet sikkenin ele geçtiğinden söz edilmektedir. Bk. Marksteiner-Schuh 2008, 45.

13 Demre-Myra Aziz Nikolaos Kilisesi'nde, 1989-2005 yılları arasında gerçekleşmiş kazılarda bulunmuş 96 adet sikkeden söz eden bir yayın olmakla beraber, Bizans sikkelerinin sayısına ve birimlerine ilişkin detaylı bilgi içermediği için değerlendirmeye-karşılaştırmaya alınmamıştır (Bulgurlu 2007, 121-128).

14 Doç. Dr. A. Tolga Tek'ten alınan bilgiye göre, 2006 yılı itibari ile Fethiye Müzesi'nde, müzenin antik sikke koleksiyonda bir çalışma gerçekleştirilmiş. Ancak henüz yayınlanmamış olan bu çalışmada 687 adet Bizans sikkesi tespit edilmiştir. Bilgileri benimle paylaşan Doç. Dr. A. Tolga Tek'e ayrıca teşekkür ederim.

15 Bu formül ile her 1000 sikkede senelik sikke kaybı görülmektedir ve binlerce örnek sahip olduğu ifade edilen sikke bulunan yerler ile çok daha az sayıda sikke verisi olanlar doğru bir orantı içinde karşılaştırılabilmektedir. Formül ilk kez 1960 yılından D. M. Metcalf tarafından kullanılmıştır. Detaylı bilgi için bk. Metcalf 1960, 429-44; Demirel-Gökalp 2015a, dn. 9.

16 Periyotlar ve tarihsel aralıkları şöyledir: Periyot 1: 491-527; Periyot 2: 527-565; Periyot 3: 565-582; Periyot 4: 582-610; Periyot 5: 610-641; Periyot 6: 641-717; Periyot 7: 717-802; Periyot 8: 802-867; Periyot 9: 867970; Periyot 10: 970-1030) Periyot 11: 1030-1050; Periyot 12: 1050-1081; Periyot 13: 1081-1453.

17 Bu veriler için tarihlenebilir sikkeler esas alınmıştır. Yani "Erken Bizans" diye adlandırımış, imparatorları belli olmayan sikkeler veri kapsamında değerlendirilmemiştir. Sikkelerin basıldıkları tarihler esas alınarak yapılan bu periyotlarda dar ya da daha geniş aralıklara indirgenebilen gruplar olabilir. Örneğin 9. Peiyot MS 867-970 yılları arasını (103 yıl) içerirken; 13. Periyot MS $1081-1453$ yılları arasını yani 372 yılı kapsamaktadır. Periyotlarda alınan kıstas, söz konusu periyot bulgularının tamamının sayısal olarak sunulabilmesidir. Anadolu'da Bizans toprak kayıplarının başladığı MS 1071 yılı sonrası bronz sikke dolaşımı azalır ve MS 1081 yılı sonrası neredeyse görülmez. Söz konusu bulguyu kanıtlayan çalışmalar için bk. Demirel-Gökalp 2007; 2011, 191200; 2015b, 849-856. 


\begin{tabular}{|c|c|c|c|c|c|c|c|c|c|c|c|c|}
\hline \multirow[b]{3}{*}{$\begin{array}{c}\text { Periyotların } \\
\text { Tarihsel } \\
\text { Aralığı }\end{array}$} & \multirow[b]{3}{*}{$\begin{array}{c}\text { Perlyot } \\
\text { Uzunluğ }\end{array}$} & \multicolumn{10}{|c|}{ LIKYA } & \multirow[t]{3}{*}{ Toplam } \\
\hline & & \multicolumn{2}{|c|}{ Arykanda } & \multicolumn{4}{|c|}{ Patara-Dereağzi } & \multicolumn{2}{|c|}{ Kaunos } & \multicolumn{2}{|c|}{ Olympos } & \\
\hline & & $\begin{array}{l}\text { Periyot } \\
\text { Başina } \\
\text { DOssen } \\
\text { SIkke }\end{array}$ & $\%$ & Patara & Dereağzı & $\begin{array}{l}\text { Perlyot } \\
\text { Başina } \\
\text { Dossen } \\
\text { SIkke }\end{array}$ & $\%$ & $\begin{array}{l}\text { Perlyot } \\
\text { Başina } \\
\text { DOssen } \\
\text { SIkke }\end{array}$ & $\%$ & $\begin{array}{l}\text { Perlyot } \\
\text { Başina } \\
\text { DOssen } \\
\text { Sikke }\end{array}$ & $\%$ & \\
\hline $491-527$ & 36 & 1 & 0,95 & 1 & 0 & 1 & 1,56 & 1 & 0,49 & 4 & 4,62 & 7 \\
\hline 527.565 & 38 & 1 & 0,9 & 2 & 1 & 3 & 4,15 & 7 & 3,28 & 7 & 7,67 & 18 \\
\hline $565-582$ & 17 & 5 & 10,14 & 2 & 2 & 4 & 12,38 & 12 & 12,6 & 6 & 14,7 & 27 \\
\hline $582-610$ & 28 & 5 & 6,15 & 1 & 1 & 2 & 3,75 & 14 & 8,92 & 2 & 2,97 & 23 \\
\hline $610-641$ & 31 & 0 & 0 & 1 & 1 & 2 & 3,39 & 21 & 12,09 & 1 & 1,34 & 24 \\
\hline $641-717$ & 76 & 1 & 0,45 & & 2 & 2 & 1,38 & 1 & 0,23 & 0 & 0 & 4 \\
\hline $717-802$ & 85 & & 0 & & 0 & 0 & 0 & 0 & 0 & 0 & 0 & 1 \\
\hline $802-867$ & 65 & & 0 & & 1 & 1 & 0,8 & 0 & 0 & 0 & 0 & 1 \\
\hline $867-970$ & 103 & 1 & 0,33 & & 0 & 0 & 0 & 0 & 0 & 0 & 0 & 1 \\
\hline $970-1030$ & 60 & 1 & 0,57 & & 3 & 3 & 2,63 & 0 & 0 & 0 & 0 & 4 \\
\hline $1030-1050$ & 20 & 14 & 24,13 & 1 & 0 & 1 & 2,63 & 0 & 0 & 4 & 8,33 & 19 \\
\hline $1050-1081$ & 30 & & 0 & & 0 & 0 & 0 & 0 & 0 & & 0 & \\
\hline $1081-1453$ & 372 & & 0 & & 0 & 0 & 0 & 0 & 0 & 0 & 0 & \\
\hline Toplam & & 29 & & & 19 & & & 56 & & 24 & & 128 \\
\hline
\end{tabular}

Fig. 5. Arykanda, Patara,Dereağzı, Kaunos ve Olympos Kazılarında Bulunan Bizans Bronz Sikkelerin Yıl-Adet-Yüzde Ilişskileri

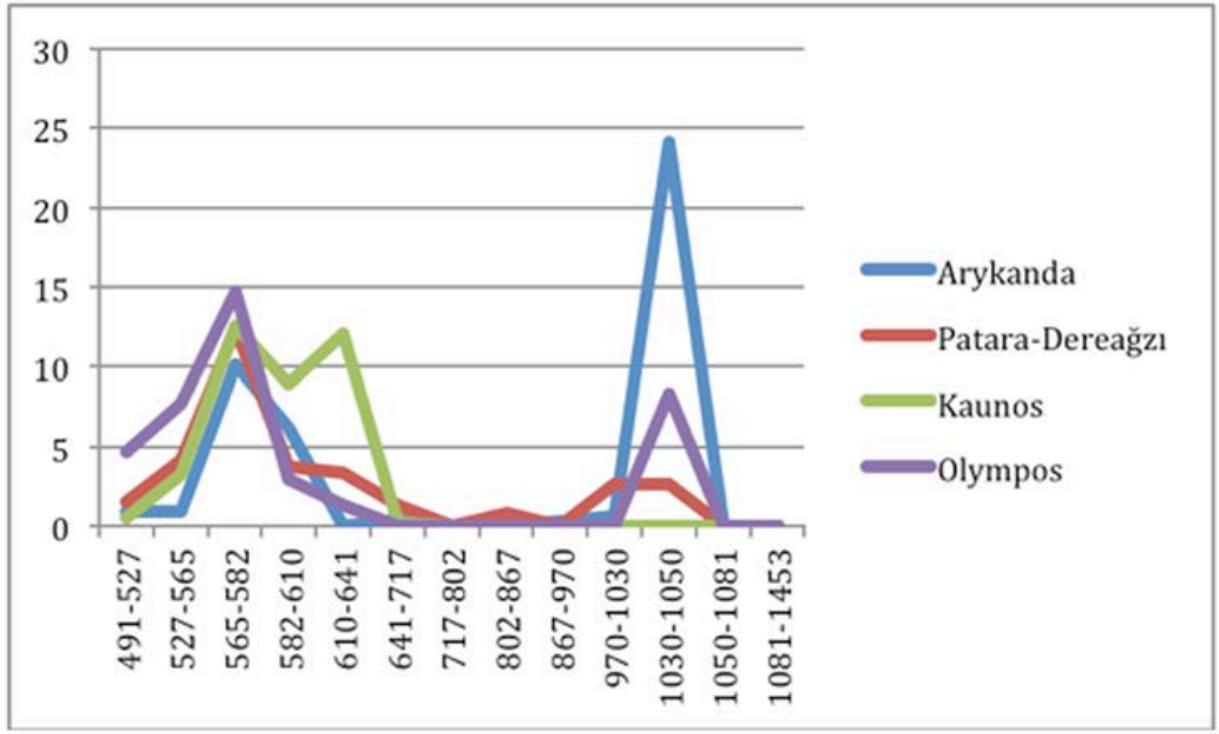

Fig. 6. Arykanda, Patara, Dereağzı, Kaunos ve Olympos Kazılarında Bulunan Bizans Bronz Sikkelerin Periyotlara Göre Dağılımı

Patara ve Dereağzı, Bizans sikke buluntularının sayısı az olduğu için bir arada ele alınmıştır. 1989-2001 yılları arasında Patara'da ${ }^{18}$ yapılan kazılarda 8, Dereağzı'nda ${ }^{19}$ ise 11 Bizans sikkesi tespit edilmiştir. Kaunos'da ${ }^{20}$ 1965-2002 yılları arasındaki kazı çalışmalarında kaydedilmiş 58 Bizans sikkesinden, 1'i belirsiz ve diğer 1'i gümüş olduğu için istatistiksel değerlendirmeye alınmamış, dolayısıyla Kaunos sikkeleri 56 adet üzerinden hesaplanmıştır. Arykanda'da ${ }^{21}$ ise 1971-2000 yılları arasında gerçekleştirilen kazılarda bulunan 29 adet Bizans sikkesi formüle edilmiştir. 2009 -2012 yılları arasında Olympos'ta gerçekleştirilen kazılarda bulunan Bizans sikkelerinden imparatoru/darphanesi/birimi belli olan 24'ü istatistiksel karşılaştırma için kullanılmıştır.

18 Özüdoğru 2002, 94-96.

19 Gregory 1993, 149-152.

20 Çizmeli-Öğün 2006, 339-349; 2007, 39-73.

21 Tek 2002. 
Likya bölgesinde arkeolojik kazı çalışmaları gerçekleştirilen kentlerden, sınırlı sayıda kentlerin sikke buluntularını temsil eden örnekler üzerinden elde edilen grafik, Fig. 5'te yer almaktadır. Buna göre karşılaştırılan kentlerin Erken Bizans döneminde sikke sayısındaki artış paralellik göstermektedir ${ }^{22}$. Ancak bununla birlikte, 3., 4. ve 5. periyotlardaki Kaunos sikkelerindeki artış Arykanda, Olympos, Patara-Dereağzı örnekleriyle benzer değildir. Arykanda, Olympos, Patara-Dereağzı buluntularının Kaunos'a benzemeyen kendi içlerindeki tutarlılık, MS 602-629 yılları arasındaki Bizans-Sasani Savaşlarının, ${ }^{23}$ yarattığı kargaşa ile açıklanabilir. Dört kentte de benzer olan MS 641 yılı sonrası başlayan ve MS 970 yılına dek süren neredeyse yok denecek kadar az olan sikke darbı ise, MS 644 yılı sonrası ve MS 660 yılından itibaren -Emevi devletinin kurucusu Muaviye ile- sürekli hale gelen Müslüman Arapların Anadolu'ya saldırılarıyla ilişkilendirilebilir ${ }^{24}$. Bizans tarihinde MS 641-842 yılları arası Karanlık Dönem olarak adlandırılmıştır. Bu dönemde imparatorluk, Anadolu'da devam eden Arap akınları ve ikonaklazma akımı sonucu iktisadi ve siyasi açıdan çok yıpranmıştır. Yine bu dönemde, Anadolu'da ve Akdeniz'de Arap akınları sonucu kentler fakirleşmiş ya da terkedilmiştir. Dolayısıyla kentlerin tarihsel süreçte bilinen fakirleşmesi ve boşaltılmasına bağı olarak da, sikke buluntuları da önemli miktarda azalmaktadır²5. MS 9701050 yılları arasındaki sikke dağılımını veren 10. ve 11. periyotlarda sikke buluntuları Kaunos dışında üç kentte de anonim follisler ile temsil edilmektedir. Tespit edilen anonim follisler, Heraclius sonrası başlayan ekonomik ve siyasi çöküşün Orta Bizans döneminde değiştiğini ekonomik canlılık ve hareketlilikle göstermektedir. Söz konusu kentlerde geç dönem Bizans sikkelerinin bulunmaması ise, bölgenin tarihi coğrafyası ile arkeolojik verilerinin paralellik gösterdiğini ifade etmektedir.

22 Erken Bizans Dönemi olarak adlandırılan 491-640 yılları arası yani ilk beş periyottaki sikke dolaşımındaki artış neredeyse tüm Anadolu için geçerlidir (Demirel-Gökalp 2007; 2015, 849-855).

23 Tek 2015, 120-135; Foss 1996, 25.

24 Theo. 6207 (385-386) - 6208 (387-389) - 6209 (390-391).

25 Karanlık Dönem süresince Bizans ekonomisinin çöküşü ve yetersizliğine ilişkin olarak ya da ekonomik açıdan bu düşüşü daha iyi görebilmek adına, tespit edilen tarihli sikkeler üzerinden yapılmış benzer çalışmalar ve sonuçları için bk. Lightfoot 2002, 229-239; Morrisson 2002, 909-966; Demirel-Gökalp 2007. 

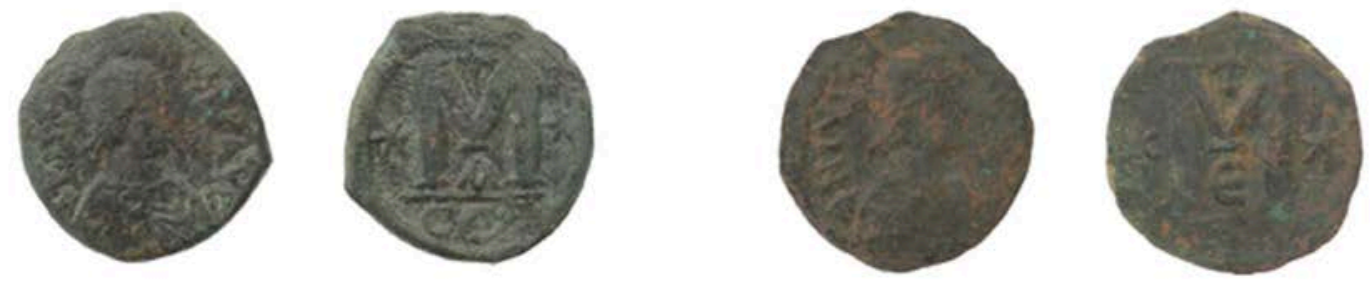

1

3



6
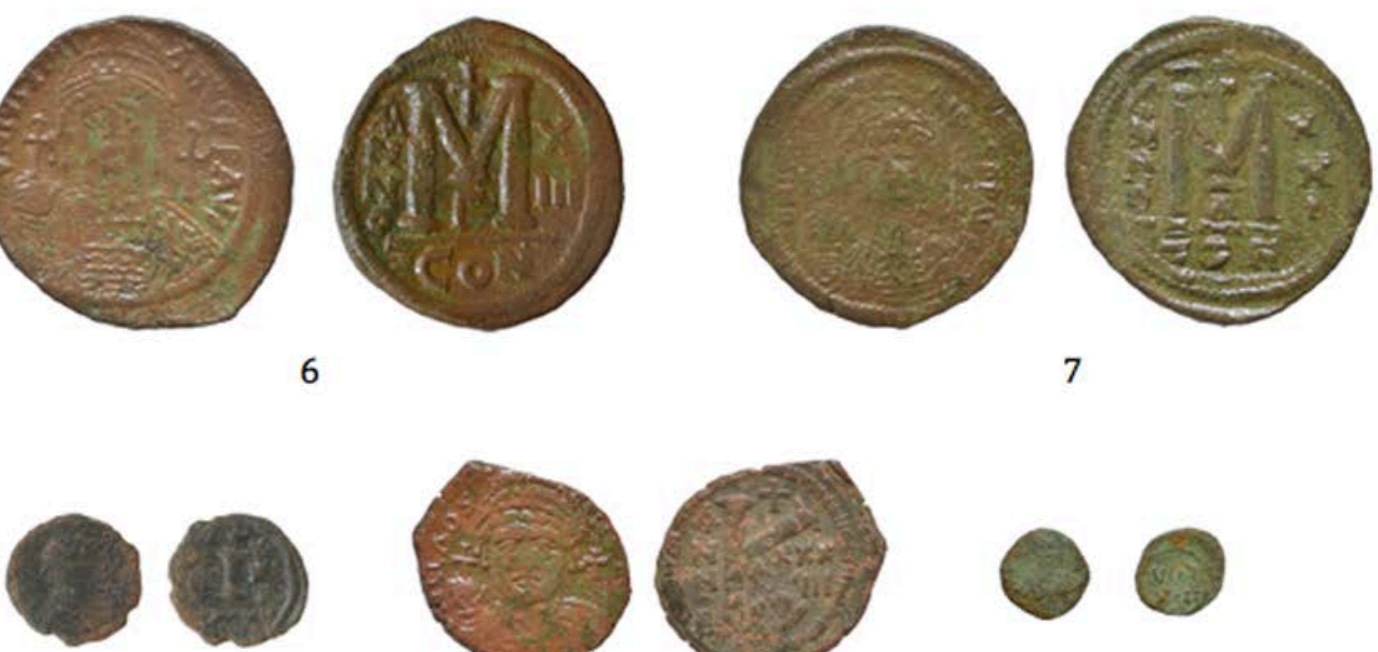

8
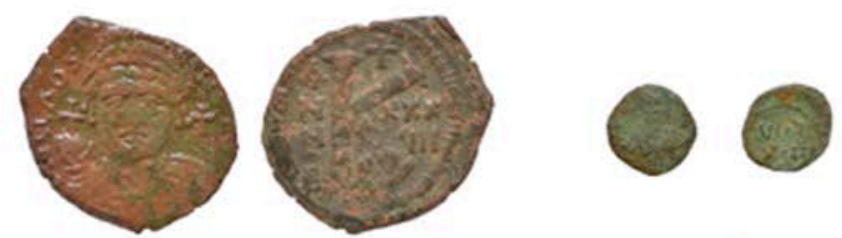

10



12

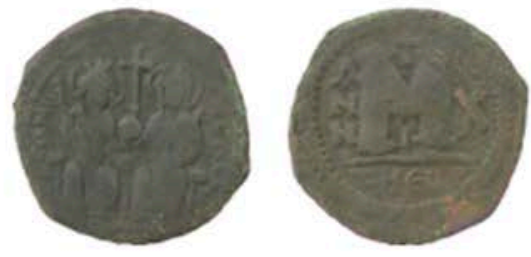

15
9

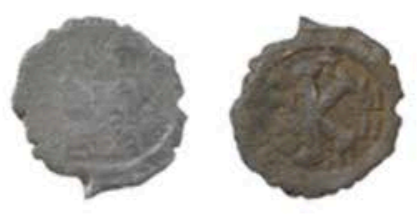

14
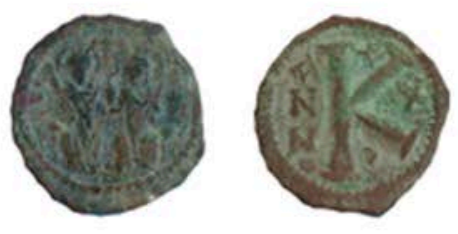

16

Fig.7. 1, 3, 6-10, 12, 14-16 Katalog No.lu Sikkeler 




17

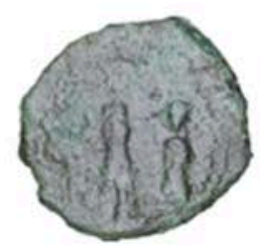

20

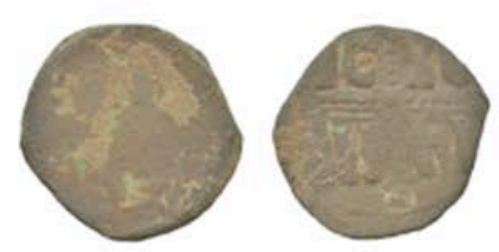

23

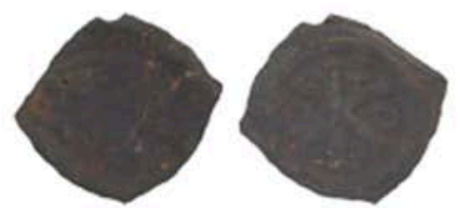

29
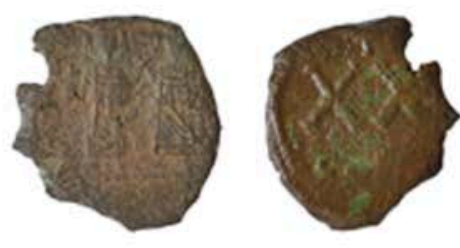

18



21
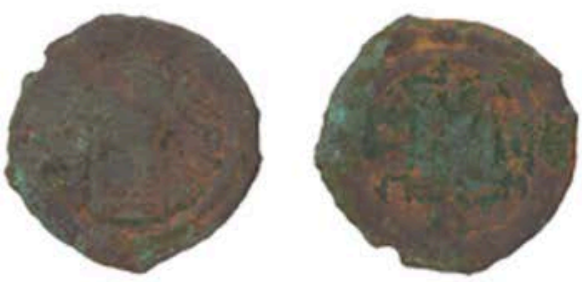

26

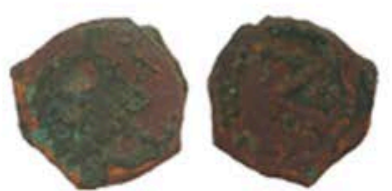

30
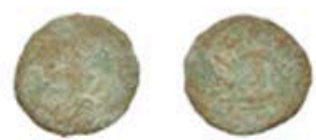

34

Fig. 8. 17-21, 23, 26, 29-30, 34 Katalog No.lu Sikkeler 


\section{KATALOG $^{26}$}

\section{IUSTINUS (10 Temmuz 518-1 Ağustos 527)}

\section{Konstantinopolis Darphanesi}

Follis

Öy.: DNIVSTI-NVSPPAVC. Büst sağa, diademli, zırhlı ve paludamentumlu.

Ay.: M, yukarıda haç, sağ ve sol boşlukta yıldız, aşağıda Of. harfi. Kesimde: CON

MS 518/27

1 AE 29/30 mm., 16.7 gr., ky.12. Of.: A; Ref.: DOC 1, s.39, no.8a.3; Env.no.: Oly/12/117; Buluntu Yeri: S5-IX Giriş Kompleksi Mekan 6 Batı (Mekanın güneyi) +5.95/5.97 (Fig. 7. 1)

2 AE 30 mm., 14.3 gr., ky.6. Of.: B; Ref.: DOC 1, s.39, no.8b.1; Env.no.: Oly/12/195; Buluntu Yeri: S5-IX Giriş Kompleksi M12-F6 +6.13 m.

3 AE 30/31 mm., 13.6 gr., ky.12. Of.: $\in$; Ref.: DOC 1, s. 40, no.8e.6; Env.no.: Oly/12/110; Buluntu Yeri: S5-IX Giriş Kompleksi Mekan 4'ün güneybatı köşesi +6.35/6.40 (Fig. 7. 3)

Öy.: Aynı

Ay. : Aynı ancak sol boşlukta yıldız, sağ boşlukta haç

MS 518/527

4 AE 29/32 mm., 17.01 gr., ky.6. Of.:?; Env.no.: Oly/12/172; Buluntu Yeri: S6-V1/G1-H1 Roma Caddesi Ortaçağ mekanı +2.37

\section{IUSTINIANUS (1 Ağustos 527-1 Kasım 565)}

\section{Konstantinopolis Darphanesi}

Follis

Öy.: DNIVSTINI-ANVSPPAVC. Büst cepheden, tüy sorguçlu miğfer giymiş, zırhlı ve kalkanlı, kalkan üzerinde süvari betimi, sağ elinde haçlı globus tutuyor. Sağ boşlukta haç.

Ay. : M, solda A/N/NO, yukarıda haç, sağda tarih, aşağıda Of. harfi. Kesimde: CON.

MS 539/540

5 AE 33/34 mm., 20.05 gr., ky.6. Of.: Г; tarih: X / III; Ref.: DOC 1, s.85, no. 38c.2; Env.no.:

\footnotetext{
${ }^{26}$ Katalogda önce sikkenin ön ve arka yüz tasvirleri, ardından sikkenin tarihi ve katalog numarası yer almaktadır. Daha sonra sikke metali, çapları, ağılıkları ve sikkenin kalıp yönü verilmiştir. Katalogda yer alan teknik kısaltmalar: AE: Bakır; Ay.: Arka Yüz; Env.no.: Kazı Envanter Numarası; ky.: Kalıp yönü; Of.: Ofis işareti; Öy.: Ön Yüz; Ref.: Referans.
}

Oly/12/124; Buluntu Yeri: S5-IX Giriş Kompleksi Mekan $17+6.61$

6 AE 36/37 mm., 21,8 gr., ky.6. Of.: Г; tarih: X / III; Ref.: DOC 1, s.85, no.38c.2; Env.no.: Oly/ 11/126; Buluntu Yeri: S6-VI/H1, +2.72 (Fig. 7. 6)

MS 547/548

7 AE 34/36 mm., 19.8 gr., ky.6. Of.: A; tarih: X / X / I; Ref.: DOC 1, s. 91, no.46a; Env.no.: Oly/ 11/88; Buluntu Yeri: S6-VI/H2, +2.60 (Fig. 7. 7)

\section{Dekanummium}

Öy.: DNIVSTINI ANVSPPAV. Büst saga dönük, diademli, zırhlı ve paludamentumlu

Ay.: I, yukarıda haç, solda A/N/N/O, sağda yıl rakamı, kesimde: CON

MS 556/557

8 AE 15/16 mm., 2.6 gr., ky.6; tarih: X / X / X; Re.: DOC 1, s.101, no.89; Env.no.: Oly/12/88; Buluntu Yeri: S5-IX Giriş Kompleksi Mekan 3Doğu (Eşik üstü) +6.24 (Fig. 7. 8)

\section{Antiokheia Darphanesi}

\section{Yarım Follis}

Öy.: Büst cepheden, tüy sorguçlu miğfer giymiş, zırhlı ve kalkanlı, kalkan üzerinde süvari betimi, sağ elinde haçlı globus tutuyor. Sağ boşlukta haç.

Ay.: K, solda A/N/N/O, yukarıda haç, sağda yıl rakamı, kesimde: $\rho$

MS 564/565

9 AE 24/26 mm., 8.9 gr., ky.11; tarih: XXX / cll; Ref.: DOC 1, s.151, no.250; Env.no.: Oly/ 11/89; Buluntu Yeri: S6-VI/H2, +2.60 (Fig. 7. 9)

\section{Kartaca Darphanesi}

Nummus ${ }^{27}$

Öy.: Yazı okunmuyor. Büst sağa

Ay. : VOT / XIII

MS 539/540

10 AE 0,9/10 mm., 0,6 gr., ky.6; Ref.: DOC 1, s.166, no.302.1; Env.no.: Oly/09/10; Buluntu Yeri: S5-IX/ Giriş Kopleksi/ Mekan 8, +6,45 (Fig. 7. 10)

\footnotetext{
${ }^{27}$ Hesaplamada kullanılan Follisin 1/40'l değerinde sikke.
} 


\section{Darphanesi Belirsiz}

\section{Pentanummium}

Öy.: Büst sağa, diademli ve paludamentumlu.

Ay. : $\mathrm{V}$

MS 538/565

11 AE 10/11 mm., 1.00 gr., ky.12; Ref.: DOC 1, S.192, no.369.2; Env.no.: Oly/09/23; Buluntu Yeri: S5-IX/ Giriş Kopleksi/ Mekan 8, +6,38

\section{IUSTINUS (15 Kasım 565-5 Ekim 578)}

\section{Konstantinopolis Darphanesi}

\section{Follis}

Öy.: DNIVSTI-NVSPPAVC. II. Iustinus ve Sophia tahta oturuyorlar, cepheden. II. Iustinus sağ elinde haçlı globus, Sophia sağ elinde haçlı asa tutuyor. Her ikisinin de başında nimbus var.

Ay. : $M$, solda $A / N / N / O$, yukarıda kristogram (ya da haç), sağda yıl rakamı, aşağıda Of. harfi. Kesimde: CON

MS 569/570

12 AE 27/29 mm., 9 gr., ky.6. Of.: $\Delta$; tarih: 4; Ref.: DOC 1, s.206, no. 26c; Env.no.: Oly/ 12/100; Buluntu Yeri: S5-IX Giriş Kompleksi Mekan 3- Doğu (eşik üstü) +6.24 (Fig. 7. 12)

\section{Nikomedia Darphanesi}

Follis

Öy.: DNIVSTI-NVSPPAVI. II. Iustinus ve Sophia tahta oturuyorlar, cepheden.

Ay. : $M$, solda $A / N / N / O$, yukarıda haç, sağda yıl rakamı. Kesimde: NIKO

MS ?

13 AE 29/30 mm., 13.5 gr., ky.6. Of.: B; tarih:?; Env.no.: Oly/12/157; Buluntu Yeri: S6-V1/F1 Köprü Caddesi +2.27

\section{Yarım Follis}

Öy.: DNIVSTI-NVSPPAVC. II. Iustinus ve Sophia tahta oturuyorlar, cepheden, başları arasında haç var

Ay. : K, solda A/N/N/O, yukarıda haç, sağda yıl rakamı. Kesimde: $\mathrm{NI}$

MS 573/574

14 AE 20/22 mm., 5.1 gr., ky.6; tarih: ৎl / II; Ref.: DOC 1, s.233, no.111; Env.no.: Oly/12/186; Buluntu Yeri: S5-IX/D6-Avlu Giriş Kompleksi (Fig. 7. 14)

\section{Antiokheia Darphanesi}

Follis
Öy.: Yazı silik. II. Iustinus ve Sophia tahta oturuyorlar, cepheden, aralarında uzun haçlı globus tutuyorlar. Ellerinde uzun asa ve nimbuslular.

Ay.: M, solda A/N/N/O, yukarıda haç, sağda yıl rakamı, aşağıda Of. harfi. Kesimde: THEUP'

MS 574/575

15 AE 28 mm., 10.06 gr., ky.6. Of.: 「; tarih: X; Ref.: DOC 1, s.245, no.157a.1; Env.no.: Oly/ 12/165; Buluntu Yeri: S6-,V1 Roma Caddesi Batı Kanad Mekanı İçi +2.50 (Fig. 7. 15)

\section{Yarım Follis}

Öy.: Yazı silik. II. Iustinus ve Sophia tahta oturuyorlar, cepheden, aralarında uzun haçlı globus tutuyorlar. Ellerinde uzun asa.

Ay.: K, solda A/N/N/O, yukarıda haç, sağda yıl rakamı. Kesimde: $\rho$

MS 574/575

16 AE 24 mm., 7.82 gr., ky.6; tarih: X; Ref.: DOC 1, s. 247, no.170.1; Env.no.: Oly/09/35; Buluntu Yeri: S5-IX Giriş Kompleksi, Mekan 8, kod: +6.36 (Fig. 7. 16)

\section{MAURICIUS TIBBERIUS (13 Ağustos 582- 25 Kasım 602)}

\section{Antiokheia Darphanesi}

\section{Follis}

Öy.: ONmAЧГІ CNPAЧT. Büst cepheden, konsul kıyafetli, yonca biçimli süslü taçlı. Sağ elinde mappa, sol elinde kartallı asa tutuyor.

Ay.: $M$, solda $A / N / N / O$, yukarıda haç, sağda yıl rakamı, aşağıda Of. harfi. Kesimde: $\tau H \in U P^{\prime}$

MS 602

17 AE 26/28 mm., 9.9 gr., ky.6. Of.: Г; tarih: X / $\mathrm{XI}$; Ref.: DOC 1, s.345, no.173; Env.no.: Oly/11/103; Buluntu Yeri: S6-VI/H1, +2.722.55 (Fig. 8. 17)

\section{FOCAS (23 Kasım 602- 5 Ekim 610)}

\section{Konstantinopolis Darphanesi}

\section{Yarım Follis (tip 1)}

Öy.: dNFOCA-PPAVC. Solda Focas, ayakta, haçı taçlı ve khlamys giyimli. Sağ elinde haçlı globus tutuyor. Sağda Leontia, ayakta, sağ elinde çapraz haçlı asa tutuyor. Başları arasında haç var.

Ay.: XX, yukarıda haç, kesimde CON ve sonda Of.harfi

MS 602/603

18 AE 20/25 mm., 6.5 gr., ky.12. Of.:?; Env.no.: 
Oly/11/107; Buluntu Yeri: S6-VI/H1, +2.722.55 (Fig. 8. 18)

\section{Nikomedia Darphanesi}

\section{Yarım Follis}

Öy.: dmFOCAS. Büst cepheden, konsül kıyafetli, haçlı taç giyiyor. Sol elinde haç tutuyor.

Ay. : XX, yukarıda haç, sağda yıl rakamı, kesimde NIKO, sonra Of. Harfi

MS 606/607

19 AE 18 mm., 4.6 gr., ky.6. Of.:?; tarih: 4; Env.no.: Oly/11/78; Buluntu Yeri: Giriş kompleksi-S5-IX-Mekan 5, +6,20 -6,10 (Fig. 8. 19)

\section{HERACLIUS (5 Ekim 610- 11 Ocak 641)}

\section{Konstantinopolis Darphanesi}

\section{Follis (Tip III)}

Öy.: Yazı yok. Üç figür ayakta, cepheden. Ortada Heraclius, sağda Heraclius Constantine, solda Martina. Her biri khlamys ve haçlı taç giyimliler, sağ ellerinde haçlı globus var.

Ay.: $M$, yukarıda haç, solda A/N/NO, sağda yıl rakamı, aşağıda Of. Harfi, kesimde: CON

MS ?

20 AE 26 mm., 9.9 gr., ky. 12. Of.: B; tarih:?; Env.no.: Oly/11/94; Buluntu Yeri: S6-VI/H1, +2.72 (Fig. 8. 20)

\section{ANONIM FOLLIS (MS 970-1092)}

\section{B GRUBU}

Öy.: + ЄmmA-NOVHL İsa'nın büstü cepheden, haç nimbuslu, haçın her bir kolunda " $\square$ ", haçın sağ ve sol kollarının yukarısındaki boşlukta birer nokta var. İsa tunik ve himation giyimli. Sol eli ile incili tutuyor. Kitap kapağında nokta bezeme var. Sağ ve sol boşluklarda IC ve XC.

Ay. : İki basamaklı kaide üzerinde haç var. Haçın kollarının ucunda birer nokta bulunuyor. Haçın kolları arasında; IS-XS / bAS-ILE / bAS-ILE MS 1030-1035/1042(?)

21 AE 29 mm., 9.7 gr., ky.6; Ref.: DOC 3/2, s. 678, no.B.47; Env.no.: Oly/11/95; Buluntu Yeri: S6-VI/H2, +2.60 (Fig. 8. 21)

22 AE 27/29 mm., 8.2 gr., ky.6; Ref.: DOC 3/2, s. 678, no.B.47; Env.no.: Oly/11/90; Buluntu Yeri: S6-VI/H1, Yüzey

\section{GRUBU}

Öy.: + ЄmmA-NOVHL İsa Antiphonetes'in dizlerine kadar betimlenmiş figürü, cepheden sakallı, haç nimbuslu, haçın her bir kolunda tek nokta bezeme var. İsa tunik ve himation giyimli. Sağ elini takdis pozisyonunda yukarı kaldırmış, sol eli ile incil tutuyor. Kapağın üzerinde bordür içinde nokta bezeme var. Sağ ve sol boşlukta IC ve XC.

Ay.: Mücevher taşları ile süslü haç, haçın kolları ucunda birer nokta, kolları arasında ise IC-XC / NI-KA

MS 1042(?)/1050

23 AE 23/25 mm., 7.9 gr., ky.6; Ref.: DOC 3/2, s. s. 682, no.C.19; Env.no.: Oly/11/129; Buluntu Yeri: S6-VI/H1, +2.45 (Taban Üstü) (Fig. 8. 23)

$24 \mathrm{AE}$ 23/24 mm., 7 gr., ky.6; Env.no.: Oly/ 11/124; Buluntu Yeri: S6-VI/H2, +2.32-2.60

İmparatoru Okunamayan Erken Bizans Dönemi Sikkeleri (MS VI-VII. Yüzyıl)

\section{Konstantinopolis Darphanesi}

\section{Follis}

Öy.: Yazı okunmuyor. Profil bust sağa dönük. Ay. : M, yukarıda haç, sağda yıldız, kesimde: CON $25 \mathrm{AE} 30$ mm., 16.5 gr., ky.6. Of.:?; Env.no.: Oly/12/86; Buluntu Yeri: S5-IX Giriş Kompleksi Mekan 3- Doğu mekanının kuzey batı köşesi +5.90

Öy.: Yazı okunmuyor. Büst cepheden, tüy sorguçlu miğfer giymiş, zırhlı ve kalkanlı, kalkan üzerinde süvari betimi, sağ elinde haçlı globus tutuyor.

Ay. : $M$, solda $A / N / N O$, yukarıda haç, sağda tarih, aşağıda Of. harfi. Kesimde: CON.

26 AE 30 mm., 10.08 gr., ky.6. Of.:?; tarih: II(?); Env.no.: Oly/12/82; Buluntu Yeri: S5-IX Giriş Kompleksi Mekan 3- Doğu mekanının batıSı.+5.85/5.90 (Fig. 8. 26)

İmparator ve Darphanesi Okunamayan Erken Bizans Dönemi Sikkeleri (MS VI-VII. Yüzyıl)

\section{Yarım Follis}

Öy.: Cepheden, ayakta iki figür

Ay. : K

27 AE 21/22 mm., 4.7 gr., ky.6; tarih:?; Env.no.: Oly/11/80; Buluntu Yeri: S6- VI/H1 - Sur önü, $+2,60$

Öy.: Büst cepheden

Ay. : K, yukarıda haç, solda A /N/N/O, sağda yıl rakamı, aşağıda Of.harfi

28 AE 19 mm., 6.2 gr., ky.?; Of.:?; tarih: III; Env.no.: Oly/12/87; Buluntu Yeri: S5-IX Giriş 
Kompleksi Mekan 3- Doğu mekanının kuzey batı köşesi +5.90

29 AE 21/22 mm., 5.8 gr., ky.12. Of.: Г; tarih: 4; Env.no.: Oly/12/101: Buluntu Yeri: S5-IX Giriş Kompleksi Mekan 3- Doğu (eşik üstü) +6.24 (Fig. 8. 29)

Öy.: Okunmuyor

Ay. : Aynı

30 AE 20/21 mm., 5.6 gr., ky.?; Of.:?; tarih:?; Env.no.: Oly/12/85; Buluntu Yeri: S5-IX Giriş Kompleksi Mekan 3- Doğu mekanının güney batı köşesi +5.98/+6.05 (Fig. 8. 30)

31 AE 19/20 mm., 5.1 gr., ky.?; Of.:?; tarih:?; Env.no.: OLY/12/80; Buluntu Yeri: S5-IX Giriş Kompleksi Mekan 3-Doğu Mekanının kuzeybatı köşesi +5.90 .

32 AE 19/20 mm., 5.1 gr., ky.?; Of.:?; tarih: ?; Env.no.: Oly/12/81; Buluntu Yeri: S5-IX Giriş Kompleksi Mekan 3- Doğu (eşik üstü) +6.24.

\section{Dekanummium}

Öy.: Yazı okunmuyor. Büst cepheden

Ay. : X, yukarıda haç

33 AE 11 mm., 1 gr., ky.6; Env.no.: Oly/12/52; Buluntu Yeri: S5-IX Giriş Kompleksi Mekan 18 - döşeme üzerinde. +667 .

Öy.: Okunmuyor

Ay. : I, solda $A / N / N / O$

$34 \mathrm{AE}$ 13/14 mm., 1,7 gr., ky.?; Env.no.: Oly/ 11/109; Buluntu Yeri: S6-VI/H1, +2.72-2.55 (Fg.8.34)

\section{Pentanummium}

Öy.: Yazı okunmuyor, profil büst

Ay. : $\Theta$

$35 \mathrm{AE}$ 12/14 mm., ,6 gr., ky.6; Env.no.: Oly/ 09/03; Buluntu Yeri: S5-IX/ Giriş Kopleksi/ Mekan 8/ sondaj, +6,17 
Bulgurlu 2007

Bulut - Şengül 2014

Borchhardt 1999

Demirel-Gökalp 2007

Demirel-Gökalp 2011

Demirel-Gökalp 2015a

Demirel-Gökalp 2015b

Demirel-Gökalp - Yıldırım 2010

DOC 1

DOC $3 / 2$

Foss 1996

Gregory 1993

Atik-Korkmaz et al. 2016

Lightfoot 2002

Marksteiner - Schuh 2008

Morrisson 2002

Olcay-Uçkan et al. 2006

Olcay-Uçkan et al. 2011

Olcay-Uçkan 2016

\section{Zeliha DEMIREL GÖKALP}

\section{BİBLIYOGRAFYA}

V. Bulgurlu, "Demre-Myra Aziz Nikolaos Kilisesi Kazısında Bulunan Sikkeler Hakkında Notlar". Eds. K. Dörtlük et al., III. Uluslararası Likya Sempozyumu 07-10 Kasım 2005 Antalya, Sempozyum Bildirileri, vol. I. Antalya (2007) 121-128.

S. Bulut - M. Şengül, "2009-2012 Yılları Andriake Kazı Sikkeleri ve Yerleşim Tarihine Katkıları". Eds. K. Dörtlük, O. Tekin - R. B. Seyhan, Birinci Uluslararası Anadolu Para Tarihi ve Nümismatik Kongresi Bildiriler Kitabı, 25-28 Subat 2013. İstanbul (2014) 79-110.

J. Borchhardt, Limyra Zemuri Taşları. Çev. G. Yümer. İstanbul 1999.

Z. Demirel-Gökalp, Yalvaç ve Isparta Arkeoloji Müzelerinde Bulunan Bizans Sikkeleri. Yayınlanmamış Doktora Tezi, Anadolu Üniversitesi. Eskişehir 2007.

Z. Demirel Gökalp, “Malatya Arkeoloji Müzesi'ndeki Bizans Sikkelerinin Değerlendirilmesi". XIV. Ortaçağ ve Türk Dönemi Kazıları ve Sanat Tarihi Araştırmaları Sempozyumu 20-22 Ekim 2010. Konya (2011) 191-200.

Z. Demirel Gökalp, "Bilecik Müzesi'ndeki Bizans Bronz Sikkeleri". TÜBAKED XII (2014) 11-28.

Z. Demirel Gökalp, "Byzantine Bronze Coins Found in Anatolia and Their Circulation". Eds. P. M. Militello - H. Öniz. Proceedings of the 15th Symposium of the Mediterranean Archaeology, held at the University of Catania between 3-5 March 2011, vol. II. Oxford (2015) 849-856.

Z. Demirel Gökalp - Ş. Yıldırım, "Lykia Olympos’unda Bir Restitüsyon Denemesi". Adalya XIII (2010) 367-387.

Eds. A. R. Bellinger - P. Grierson, Catalogue of the Byzantine Coins in the Dumbarton Oaks Collection and in the Whittemore Collection, vol I: Anastasius I to Marice 491-602. Washington 1966.

Eds. A. R. Bellinger - P. Grierson, Catalogue of the Byzantine Coins in the Dumbarton Oaks Collection and the Whittemore Collection, vol. III/1-2: Leo I/ to Nicephoros // 717-1081. Washington 1973.

C. Foss, "The Cities of Pamphylia in the Byzantine Age". Cities, Fortresses and Villages of Byzantine Asia Minor. Aldershot (1996) 1-62.

T. E. Gregory. "The Ancient and Byzantine Coins". Ed. J. Morgenstein. The Fort At Dereağzı. Tübingen (1993) 149-152.

S. Atik Korkmaz, M. A. Demirtaş, M. H. Sayar, S. Mimaroğlu, T. Tek, "Letoon Kutsal Alanı 2015 Yılı Arazi Çalışmaları”. Anmed XIV (2016) 71-78.

C. Lightfoot, "Byzantine Anatolia: Reassessing the Numismatic Evidence". Revue Numismatique 158 (2002) 229-239.

T. Marksteiner - U. Schuh, "Excavations at Limyra in 2007". Anmed VI (2008) 42-46.

C. Morrisson, "Byzantine Money: Its Production and Circulation". Ed. A. Laiou. The Economic History of Byzantium: From the Seventh through the Fifteenth Century. Washington (2002) 909-966.

B. Y. Olcay Uçkan et al., Lykia'da Bir Korsan Kenti, Olympos. İstanbul 2006. B. Y. Olcay Uçkan et al., "Olympos 2009". Kazı Sonuçları Toplantısı XXXII/III (2011) 80-97.

B. Y. Olcay Uçkan, “Olympos'ta Ticaret”. Eds. P. Magdalino - N. Necipoğlu, Trade in Byzantium Papers from the Third International Sevgi Gönül Byzantine Studies Symposium. İstanbul (2016) 489-501. 
Olcay-Uçkan - Öztaşkın 2016 B. Y. Olcay Uçkan - G. K. Öztaşkın, "Ateş ve Suyla Kutsanan Kent: Olympos". Eds. H. İşkan - E. Dündar, Lukka'dan Likya'ya Sarpedon ve Aziz Nikolaos'un Ülkesi. İstanbul (2016) 274-287.

Öncü 2012

Ö. E. Öncü, "Olympos Antik Kenti Roma Mimarisi Araştırmalarından Yeni Bulgular". Eds. K. Dörtlük, T. Kahya, R. Boyraz-Seyhan - T. Ertekin, Uluslararası Genç Bilimciler Buluşması I: Anadolu Akdenizi Sempozyumu, Antalya, 04-07 Kasım 2009. Antalya (2012) 273-284.

Öztaşkın 2013

G. K. Öztaşkın, Olympos Kenti Episkopeion Yapı Topluluğu. Yayınlanmamış Doktora Tezi, Anadolu Üniversitesi. Eskişehir 2013.

Özüdoğru 2002

Ş. Özüdoğru, Patara Sikke Basımları ve Patara Kazıları'ndan (1989-2001) Ele Geçen Sikkeler. Yayınlanmamış Yüksek Lisans Tezi. Akdeniz Üniversitesi. Antalya 2002.

Parman - Olcay-Uçkan 2006

E. Parman - B. Y. Olcay-Uçkan, "Olympos'un Ortaçağ Dokusu”. Eds. K. Dörtlük et al., III. Uluslararası Likya Sempozyumu, Antalya 07-10 Kasım 2005, vol. II. İstanbul (2006) 587-599.

Tek 2002

A. T. Tek, Arykanda Kazılarında Bulunan Antik Sikkeler Üzerinde Yeni Incelemeler: 1971-2000 Sezonları. Yayınlanmamış Doktora Tezi, Ankara Üniversitesi. Ankara 2002.

Tek 2015

A. T. Tek, "Side Sikke Buluntuları Işığında MS 622/3'de Pamphylia'ya 'Olası' Bir Sasani Saldırısı". Colloquium Anatolicum XIV (2015) 120-135.

Theo.

(= Theophanes, Chronicle)

Kullanılan Metin ve Çeviri: Theophanes Confessor, The Chronicle of Theophanes Confessor. Byzantine and Near Eastern History A.D. 284-813). Trans. C. Mango - R. Scott. Oxford 1997. 